\title{
ASISTENCIA MÉDICA UNIVERSAL Y ¿GRATUITA? A LOS EXTRANJEROS EN ESPAÑA: EL DICTAMEN MOTIVADO 2009/2341 DE LA COMISIÓN EUROPEA CONTRA ESPAÑA
}

\section{UNIVERSAL ¿FREE? MEDICAL ASSISTANCE FOR FOREIGNERS IN SPAIN: REASONED OPINION 2009/2341, FROM THE EUROPEAN COMMISSION AGAINST SPAIN}

\author{
Cristina Sánchez-Rodas Navarro \\ Catedrática de Derecho del Trabajo y Seguridad Social \\ Universidad de Sevilla \\ Código ORCID ID: 0000-0001-9780-7860
}

Se escriben continuamente "ríos de tinta" sobre la supuesta insostenibilidad financiera del sistema de pensiones contributivas obviándose sistemáticamente en el debate político que legalmente no existe ningún impedimento para que la financiación de las pensiones contributivas sea mixta: cotizaciones y tributos.

Y con tributos se financia como regla general la sanidad pública en España, con excepciones muy puntuales. Por eso resulta tan sorprendente que dados los problemas que ésta última atraviesa y sin haberse incrementado previamente los recursos humanos y materiales de los hospitales públicos, se haya reabierto el debate político sobre la asistencia sanitaria a los extranjeros en situación administrativa irregular.

Tomando como referentes las SSTC 139/2016, 134/2017 y 18/2018, podremos responder preguntas básicas tales como:

1.¿El sistema sanitario público español es universal? Sí, en tanto "que no puede excluirse a ninguna persona del derecho a ser atendido. Pero ese derecho se configura y concreta de acuerdo con lo que dispone la Ley, que debe regular las distintas condiciones y términos en los que se accede a las prestaciones y servicios sanitarios".

2.¿El sistema sanitario público español es gratuito? No. "Que los poderes públicos deban organizar las prestaciones y servicios necesarios para garantizar la protección de la salud, no significa que estas prestaciones hayan de ser necesariamente gratuitas para todos sus destinatarios (STC 139/2016, de 21 de julio)". Es decir, universalidad no es sinónimo de gratuidad.

3.¿Qué derechos tienen los extranjeros en situación administrativa irregular? "El derecho de los extranjeros a beneficiarse de la asistencia sanitaria será determinado y podrá ser limitado por las normas correspondientes. El legislador puede tomar en consideración el dato de su situación legal y administrativa en España".

A mayor abundamiento, la STC 95/2000, de 10 de abril, reconoció que "la asistencia sanitaria pública no es un Derecho que haya de ser reconocido a los extranjeros en igualdad de condiciones que a los españoles".

e-Revista Internacional de la Protección Social, ISNN 2445-3269. 2018, Vol. III, Nº 1

http://dx.doi.org/10.12795/e-RIPS.2018.i02.01. Páginas:1-2.

Página 1 
A su vez, dentro del colectivo de extranjeros hay diferentes regímenes jurídicos: nacionales de Estados en los que se aplique el Derecho de la Unión Europea y los nacionales de Terceros Estados. Y en este último grupo, a su vez, entre residentes legales y quienes se encuentren en situación administrativa irregular.

Respecto a estos últimos resulta clave el artículo 3 ter de la Ley 16/2003, de Cohesión y Calidad del Sistema Nacional de Salud, introducido por el Real Decreto-ley 16/2012 y que restringió los derechos que en materia de asistencia sanitaria reconocía la legislación anterior a los inmigrantes irregulares empadronados. La normativa anterior a la reforma no tenía parangón con el resto de los países de la UE ya los extranjeros en situación irregular se equiparaban en el ámbito de la asistencia sanitaria a los españoles, incluso por lo que se refería a las técnicas de reproducción asistida.

Tras la reforma, el ordenamiento español garantizó y garantiza a los inmigrantes en situación irregular asistencia sanitaria en los siguientes supuestos: de urgencia por enfermedad grave o accidente, cualquiera que sea su causa, hasta la situación de alta médica; asistencia al embarazo, parto y postparto; y en todo caso, los extranjeros menores de dieciocho años recibirán asistencia sanitaria en las mismas condiciones que los españoles.

Pese a las transferencias del Estado a las CC.AA. en materia de asistencia sanitaria, la STC 134/2017 recuerda que "la normativa básica estatal cierra toda posibilidad a las normas autonómicas de desarrollo para configurar un sistema de acceso a las prestaciones sanitarias que no atienda a los conceptos de asegurado o de beneficiario que han establecido las bases recogidas en el artículo 3 de la Ley 16/2003”.

4. Desde la perspectiva del Derecho de la UE ¿qué efectos tendría reformar la Ley $16 / 2003$ y extender el derecho a la asistencia sanitaria a los extranjeros independientemente de su situación administrativa en España? Al ser la asistencia sanitaria un riesgo incluido en el ámbito de aplicación material del Reglamento $883 / 2004$ de coordinación de sistemas de Seguridad Social, los titulares de una tarjeta sanitaria española tendrían derecho a obtener la tarjeta sanitaria europea y percibir asistencia sanitaria en otros países de la UE, con cargo exclusivamente al Estado español.

A mayor abundamiento, por aplicación del principio de igualdad de trato -piedra angular del Derecho de la UE- si España reconociera tarjeta sanitaria a los inmigrantes en situación administrativa irregular habría de otorgarle los mismos derechos a los ciudadanos de Estados miembros de la UE aunque no residieran ni trabajaran en España. De hecho, entre los motivos que se alegan en la Exposición de Motivos del Real Decreto-ley 16/2012 para restringir los derechos sanitarios de los extranjeros en situación irregular se cita expresamente el Dictamen motivado 2009/2341, de la Comisión Europea contra España por su negativa a expedir la tarjeta sanitaria europea a personas residentes en España con derecho a recibir asistencia sanitaria con arreglo a la normativa de algunas Comunidades Autónomas.

5. ¿Es sostenible una asistencia sanitaria universal y gratuita para ciudadanos, extranjeros, residentes y no residentes? Cada cual que responda conforme su leal saber y entender.

e-Revista Internacional de la Protección Social, ISNN 2445-3269. 2018, Vol. III, N 1

http://dx.doi.org/10.12795/e-RIPS.2018.i02.01. Páginas:1-2.

Página 2 